\title{
As múltiplas faces de Duas caras: telenovela e contemporaneidade*
}

\author{
*Trabalho inicialmente apresentado ao GT. "Cultura das \\ Mídias", do XVII Encontro da Associação Nacional dos \\ Programás de Pós-Graduação em Comunicação - Compós, \\ realizado na Universidade Paulista - UNIP, São Paulo, SP, \\ em junho de 2008.
}

Geraldo Carlos do Nascimento Universidade Paulista/UNIP

SANDRA FISCHER

Universidade Tuiti do Paraná/UTP 


\section{Resumo}

Este trabalho, decorrente de uma pesquisa em andamento, tem o propósito de apresentar considerações e apontamentos introdutórios para um estudo da telenovela brasileira Duas caras (2007/2008), de autoria de Aguinaldo Silva, veiculada pela Rede Globo de Televisão. Considera aspectos atinentes, entre outros, a questões de intertextualidade, à representação da ambiguiidade e aos efeitos de valores vinculados a estes procedimentos na cultura do gênero.

\section{Palavras-chave}

Telenovela, Ambigüidade, Intertextualidade, Duas caras

\section{Abstract}

This essay aims at presenting an introductory study to the Brazilian soap opera Duas caras (2007/2008, Aguinaldo Silva), produced and exhibited by Rede Globo de Televisão. The text considers aspects related to intertextuality, particularly those focusing on the representation of ambiguity and the effects of the television dramatic culture values attached to this procedure.

\section{Key words}

Soap Opera, Ambiguity, Intertextuality,Duas caras 
osso propósito neste trabalho é apresentar algumas considerações e apontamentos a respeito da ampliação do espectro de inovações observáveis na telenovela brasileira, a partir do enfoque particular da convencionalmente chamada "novela das oito" veiculada pela Rede Globo de Televisão - programa que de segunda a sábado ${ }_{\curlyvee}$ vai ao ar, efetivamente, na faixa das vinte e uma horas. No contexto de nossas investigações este estudo sitụa-se no âmbito de um projeto de pesquisa em que tratamos do produto midiático constituído pela țelenovela, elemento de presença marcante e influente tanto na esfera restrita à cultura das mídias que operam no país quanto na dimensão mais ampla da realidade social. O presente texto segue a trilha inaugurada pelo trabalho que realizamos com a telenovela Belíssima $a_{,}^{1}$ de Șílvio de Abreu, produzida e exibida pela Rede Globo entre 07 de novembro de 2005 e 08 de julho de 2006; desta feita, concentramo-nos em Duas caras $^{2}$, de Aguinaldo Silva, a telenovela que se encontra atualmente em exibição. Visando a precisar mais adequadamente o recorte definido, abordaremos rapidamente - para efeitos de contextualização e comparação - aspectos das telenovelas que, na mesma faixa horária, foram exibidas

1. Texto de nossa autoria, publicado na Revista Comunicação midiática sob o título "Belíssima: a um passo da ambigüidade - conșiderações sobre conservadorismo e mudança na novela das oito".

2. Telenovela da Rede Globode Televisão em exibição de segunda-feira a sábado, vinte e uma horas. De autoria de Aguinaldo Silva e direção geral de Wolf Maya, teve início em 01 de outubro de 2007 e tinha término previsto para maio de 2008, por ocasião da construção deste artigo. 
pela emissora no período compreendido entre a veiculação das duas telenovelas citadas.

Sabe-se que entre os anos 1970 e 1990 a teleficção no Brasil passou, de modo geral, por um período em que sofreu uma chamada modernização - entendida pela crítica televisiva como ligada à construção e elaboração de um modelo de telenovelas que buscou deixar de lado a fórmula radiofônica dos melodramas cubanos e mexicanos ${ }^{3}$. Parece-nos que a década de 1990 e os anos 2000, por súa véz, têm sidò tempos marcados respectivamente 1) pela consolidação dessas mudanças e 2) por uma certa amplificação dessa dita modernização ${ }^{4}$. Assim, dentro dos limites impostos pelo gênero, as telenovelas do horário incorporaram soluções relativamente mais realísticas e um tanto mais inusitadas - ou ousadas - do que aquelas adótadas anteriormente. Interessa-nos ressaltàr párticularmente o caso atinente à novela das oito justamente porque se trata, no caso da emissora em pauta, de um segmento têlenovelístico tradicionalmente mais conservador: os formatos compreendidos pelas novelas das seis e das sete da noite caracterizám-se, tendencialmente, por apresentar produtos que desenvolvem histórias de épóca ou tèmáticàs dirigidas ao público presumivelmente máis jovem, nó caso do primeiro; e pelas tramas de caráter lúdico, porr vezes "experimentais" em têrmos narrativos (recorde-se, por exemplo, o caso de Guerra dos sexos e o de As filhas da mãe $)^{5}$, no horário dăs sete.

3. A esse respeito, ver: XAVIER, Ismail (2004); BORELLI, Sílvia Helena, ORTIZ, Renato \& RAMOS, José Mário (1989); COSTA, Inimá S. \& KHEL, Maria Rita (1986).

4. Alguns estudiosos, como LOPES, Maria Immacolata (2003), chamam a atenção para as mudanças que se deram a partir de 1990 atribuindo-as a umà crise vivenciada pela Rede Globo com o fim do'regime militar e a introdução da tv a cabo; época em que a emissora teve de enfrentar de modo mais acentuado também a concörrếnciá dà Rede Manchete e do SBT:

5. Telenovelas de Sílvio de Abreu exibidas pela Rede Globo de Televisão, respectivamente de 6 de juntio de 1983 a 7 de janeiro de 1984 e de 27 de agosto de 2001 a 19 de janeiro de 2002 . 
Já o dito horário das oito costuma ser preenchido por narrativas de caráter mais ortodoxo ou sisudo, comprometidas com temáticas tidas como sérias e adultas; costuma prevalecer, nesta faixa horária, o perfil mais próximo do tradicional gênero folhetinesco. Ativemo-nos ao âmbito da Rede Globo de Televisão por tratar-se da emissora que, no país, se tem destacado em termos de produção de ficção televisual e de alcance de níveis elevados de audiência.

Nossa hipótese, embasada em levantamentos ainda não definitivos, é de que desde a década de 90 as telenovelas do horário, umas mais outras menos, vêm acentuando as rupturas com a tradição, e, não obstante a diversidade temática apresentada, um eixo estrutural mais ou menos amplo tem se reiterado no horário: a exploração narrativa do que identificamos como duplicidade, ou como ambigüidade, que parece ser favorecida pelo modo de produção nãolinear, facultada pelos núcleos - em outra oportunidade trataremos deste último aspecto.

Belíssima, de Sílvio de Abreu, por exemplo, como já discutimos mais pormenorizadamente em trabalho anterior, foi centrada no entrelaçamento de relações entre o mundo da moda, dos negócios e do trabalho e o universo atinente à problemática dos dramas de caráter pessoal das personagens envolvidas. Situando a figura feminina em posição de relativa centralidade, encetou discussões que questionaram posturas estereotipadas de poder e de relacionamentos profissionais, familiares e amorosos. Não chegou a ser responsável por introduzir em sua estrutura mudanças formais de caráter excepcional; apresentou, todavia, inovações que, mesmo operadas de maneira um tanto sutil, resultaram em rupturas interessantes em relação ao esquema convencional do gênero - que promoveram, por exemplo, a pulverização de posições e papéis tradicionais, o desenvolvimento narrativo conduzido de maneira pouco previsível nas telenovelas do horário, quase à moda picaresca, pontilhado por descontinuidades e inserções atípicas; e, destacadamente, a constituição e colocação em cena de personagens ambíguas, construídas de forma multifacetada, ostentando comportamentos por vezes incomuns e quase sempre pouco apreensíveis do ponto de vista dos valores envolvidos e colocados em questão no perfil psicológico de personagens televisivos. 
Em Páginas da vida ${ }^{6}$, telenovela que sucedeu Belíssima, verificou-se também uma boa dose de ambigüidade na construção das personagens, embora de forma diversa da que ocorreu no caso do folhetim de Sílvio de Abreu: priorizou-se especificamente a figura daquelas que ocupam os lugares do vilão. Malvados e malvadas tiveram suas malfeitorias bastante relativizadas pela discussão dos motivos e pontos de vista que redundaram na prática de ações de caráter pouco ou nada louvável. Mas o que :sé observou de efetivamente pouco ordinário aconteceu no nível do enfoque temático: a novela primou pela peculiar intensificação da simples exploração das mazelas do cotidiano em detrimento da atenção especial ao excepcional e excêntrico - carácterística, aliás, usual da ficção televisiva de Manoel Carlos, também autor das recentes Mulheres apaixonadas (2003), Laços de família (2000-2001) e-Por amor (1997) -, apresentando ainda a cidade e a praia como pano de fundo, famílias em situações de nascimento e de luto, cenas singelas em praças e parques, celebrações de casamentos promissores que suavémente, no decorrer da intriga, desandam em separações desdramatizadas, rotinàs de trabalho e lazer, conflitos entre pais e filhos, a miudeza de pequenos problemas domésticos entrecortados por outros não tão pequenos envolvendo traição e desengano sucessivos, e algo rocambolescos encontros e desencontros, o escoar da mesmice do tempo. O cotidiano em questão, cumpre ressaltar, era retratado em matizes de exotismo e glamour, tonalidades em certa medida típicas da idealização folhetinesca; tratava-se, não obstante, na maior parte do tempo, da experiência cotidiana supostamente vivenciada pelas classes alta e média alta do Rio de Janeiro, que, mesmo enfrentando dificuldades e dissabores - como alcoolismo, cegueira e outros problemas de saúde física ou mental - encontram-se consideravelmente distantes das agruras e dificuldades que permeiam a rotina da maior parte: da população brasileira, constantemente submetida à segregação econômica, à exclusão social e acuada, sem atenuantes, pela violência urbana. $O$ inusitado-digamos assim - ficou por conta

6. Telenovela de Manoel Carlos produzida e veiculada pela Rede Globo de Televisão de 10 de julho de 2006 a 3 de março de 2007. 
do fato de que, efetivamente, a telenovela ousou alçar a rotina das personagens praticamente à condição de protagonista ao ponto mesmo de se expor a manifestações de insatisfação por parte da audiência que, em diversos momentos, declarou-se entediada, como foi amplamente noticiado.

Paraíso tropical ${ }^{7}$, por sua vez, sucedendo Páginas da vida parece ter tomado novamente a orientação do rúmo seguido pốr Belíssima: caminhou pela vereda da mescla entre as relações de universos de caráter pessoal è profissional. A trama desdobrou-se de forma a atingir diversos segmentos da sociedade cariocà, praticamente sem privilegiar qualquer deles prioritária ou exclusivamente. Novamente observam-se personagens relativamente ambíguas, vilões divididos, e heróis às vezes um tanto maus - mas o que chamou mesmo a atenção foi a agilidade, pouco usual no gênero, com que se atavam e desatavam os nós da trama narrativa e o permanente deslocamento do foco de atenções, que escorregava, por entre os capítulos, de uma personagem para outra ao sabor dos conflitos que se estabeleciam e, rapidamente resolvidos, se desfaziam: o recurso enfaticamente utilizado deixava bem claro que a narrativa abandonava a necessidade de manter em suspenso um indefectível gancho para, presumivelmente, segurar o espectador até o último capítulo, quando então tudo se resolveria.

Duas caras, a sucessora de Paraíso tropical, depois de um tumultuado início com quedas vertiginosas nos índices do Ibope ${ }^{8}$ e afastamento provisório do autor, encontrava-se já na marca superior aos $40 \%$ de audiência no momento da escritura deste trabalho. Apresenta inovações que se desdobram em duas vertentes principais: uma no nível da tecnologia, posto que é a primeira telenovela a ser produzida inteiramente com recursos da digitalização, e outra no nível de sua estruturação temática, que coloca explicitamente em pauta, desde o título, a questão da ambivalência, da ambigüidade, dà duplicidade - ou, melhor, da multiplicidade - que estrutura a contemporaneidade e parece reger o viver junto na atualidade.

\footnotetext{
7. Telenovela de Gilberto Braga e Ricardo Linhares, veiculada pela Rede Globo de Televisão de 5 de março a 29 de setembro de 2007.

8. Instituto Brasileiro de Opinião Pública e Estatística.
} 


\section{Duas caras: tecnologia, ambigüidade, intertextualidade}

Duas caras inaugura no mundo das telenovelas recursos responsáveis pela alta definição: a digitalização. A nova tecnologia obrigou os atores a se adequarem aos novos cenários, maquiagens $\mathrm{e}$ figurinos. $O$ autor, por sua vez, passou a contar com soluções tecnológicas outrora inimagináveis, e pôde lançar mão de efeitos especiais, que the permitiram até construir um capítulo em que a Portelinha, favela fictícia onde transcorre boa parte da ação narrativa da telenovela, ficou às escuras com um apagão, e ușar e abusar de flashes oníricos ou hiper-reais, de locações noturnas com sítios envoltos pela bruma, alếm de poder mostrar, em segundo plano, o que acontece lá fora de uma vidraça enquanto um casal de protagonistas, por exemplo, toma sorvete numa lanchonete. É como no cinema, com a possibilidade de se explorar a profundidade de campo, graças ao poder da alta definição. Essa "maravilha", porém, só poderá șer inteiramente apreciada por toda audiência quando os receptores forem devidamente adaptados - mas já é possível sentir a diferença.

Tendo como cenário o belo, tumultuado e controverso Rio de Janeiro contemporâneo, a telenovela gira em torno da problemática cotidiana da cidade e de seus habitantes - focando particularmente a rotina da comunidade de uma favela modelo, chamada Portelinha, e a de abastados moradores de condomínios na Barra da Tijuca. A favela, que constitui o núcleo formado pelos pobres $\mathrm{e}$ desfavorecidos, é representada como um espaço onde impera a organização imposta pelo autoritarismo paternalista de seu fundador e líder comunitário, Juvenal Antena. O núcleo dos ricos e privilegiados subdivide-se em facções representativas dos muito endinheirados, dos que gozam de situação econômica confortável e dos relativamente remediados. Por entre os dois núcleos distribuem-se vilões e vilãs, mocinhos e mocinhas e um contingente de personagens que transitam pelas duas situações, ou seja: não são completamente más e nem divinamente boas. 
Em que pese a idealização da favela estilizada, quase asséptica - lindamente organizada com suas casas bem cuidadas e ruelas animadas pelo movimento da comunidade em alegre faina cotidiana - e a primariedade das oposições simplistas com que são esquematizadas algumas das oposições na trama (esposa inocente e apaixonada em contraposição à figura da amante fogosa; cafajeste perverso em contraponto à donzela ingênua; pais descompromissados e filhos abandonados), a telenovela ainda assim consegue escapar de algumas obviedades estereotipadas que, no gênero, tendem a orientar os relacionamentos interpessoais: o caso amoroso entre a branca privilegiada e o negro pobre e favelado, por exemplo, desenvolve-se de forma, pelo menos até certo ponto, desamarrada dos clichês costumeiros; Juvenal Antena, o líder da favela, é mostrado em sua plena ambivalência de patriarca autoritário, manipulador, e dirigente efetivamente preocupado com o bem estar da comunidade.

Impregnada por ambigüidades e ambivalências de toda ordem, a telenovela articula, por meio de recursos intertextuais e dialógicos, universos temáticos polêmicos e controversos que se interligam e interpenetram - tratando, entre outros, de assuntos como política e corrupção, estelionato e falsidade ideológica, homossexualidade e bissexualidade, preconceito e discriminação racial e social, permeabilidade entre classes sociais, alcoolismo, drogadição, dislexia, ensino privado, relações de poder e hierarquização social.

O que nos interessa particularmente são as questões relativas e decorrentes às ambiguiidades e às intertextualidades que permeiam as articulações narrativas e a composição das personagens, de tal forma que tudo parece ser relativizado em Duas caras, até mesmo o caráter e a configuração da dupla formada pelo vilão-mór (Marconi Ferraço, o impostor falsário e ladrão que, após uma cirurgia plástica de rosto, transmuda-se em bem sucedido executivo) e por sua mocinhaprejudicada (a ingênua Maria Paula que, tendo sua fortuna roubada por Ferraço, transforma-se em funcionária de supermercado). Assim, a questão da máscara e de suas sucessivas variações afigura-se, em termos, como a questão central da narrativa - além de que os lugares, os papéis e as atuações são, não obstante os limites do gênero, pluralizados e intercambiados em suas diversas perspectivas. 
Presença costumeira quando a mídia em questão é o cinema, notadamente quando se trata do cinema dito de arte, a ambigüidade poucas vezes dá as caras no universo midiático das telenovelas - e, quando o faz, quase sempre tende a resvalar para a pura e simples incoerência. Entendida como qualidade característica daquilo que é ambíguo, pouco apreensível (o termo ambigüidade vem do Latim ambiguu $(m)$, ambíguo; que apresenta duas faces, dois senti$\operatorname{dos}^{9}$ ), a ambiguiidade é própria da arte, da metáfora, favorece a quebra de expectativas e a plurissignificação que acompanham as rupturas poéticas - o que não parecia ser muito desejável, segundo a ótica da telenovela tradicional, para narrativas que necessitam da adesão de um espectro amplo de público que tanto acompanhe o desenrolar dos capítulos quanto seja suscetível ao pacote de ofertas de consumo que vem a eles atrelado. Nessa medida, seria conveniente a minimização ou mesmo ausência de personagens e situações ambíguas nas telenovelas: julgava-se - tudo leva a crer - que não se podia esperar que o telespectador fosse seduzido e compelido a adquirir determinado produto ou modus vivendi que implique hábitos de consumo que interessem aos anunciantes e patrocinadores, se estivesse pré-ocupado, às voltas com emaranhados de instabilidades de personagens enroladas em maçarocas que, eventualmente, fazem laço com os fios de suas próprias instabilidades particulares - o que não seria bom para a publicidade. Algo dessa lógica, no entanto, mudou.

9. No artigo referido sobre:Belíssima desenvolvemos esta questão, tentando ir um pouco mais a fundo, uma vez que ela determina todo o comportamento de um dos protagonistas daquela narrativa, gostaríamos ainda de reiterar que além de ambigüidade vir do Latim ambiguu $(m)$, ambíguo, que apresenta duas faces, dois sentidos; o vocábulo "ambigüidade", ou anfibologia (Grego amphibologia, discurso ambíguo) emprega-se em Gramática para designar os equívocos de sentido provenientes de construção defétuosa da frase ou do uso de termos impróprios. No âmbito da crítica literária, açepção mais próxima da aqui utilizada, a palavra foi introducida em 1930 por William Empson, que entende por ambigüidade "toda nuança verbal, posto ligeira, que dê lugar a diferentes reações ao mesmo fragmento de linguagem" (MOISÉS, 1999, p.20). 
No caso de Duas caras, a maior parte das personagens não apenas são multifacetadas e consideravelmente desprovidas das idealizações e das simplificações maniqueístas características do gênero, como se apresentam às voltas com entraves típicos da fragilidade humana, dos problemas enfrentados pelas pessoas que se encontram do lado de fora da tela - recurso que tende tanto a fortalecer mecanismos crítico-solidários de identificação do público com as histórias narradas (em detrimento da pura e simples adesão contemplativo-onírica passível de resultar em plena suspensão da descrença e do juízo crítico) quanto a incentivar o desenvolvimento de posturas favoráveis a atitudes de tolerância, compartilhamento ou crítica solidário-construtiva. Algumas dessas personagens, inclusive, amplificam seu caráter ambivalente também na medida em que estabelecem um certo diálogo com personagens e situações de outros universos ficcionais e até mesmo com figuras e fatos que fazem parte da realidade.

Gioconda Barreto, personagem detentora de significativa carga dramática, é um bom exemplo de ambigüidade potencializada. Rica e sofisticada esposa de um advogado bem sucedido e pouco escrupuloso, Gioconda decide conhecer a favela Portelinha, onde vive o namorado de sua filha Júlia. Durante a visita, traficantes invadem o local e ela, surpreendida, vê-se em apuros em meio ao tiroteio: atônita e chocada, sem saber como agir, desespera-se. De joelhos, mãos ensangüentadas após vã tentativa de prestar socorro e assistência a uma jovem da comunidade que acaba vítima de um disparo dos bandidos, em clara alusão a uma passagem de Macbeth, de William Shakespeare, Gioconda contorce as mãos, esfregando-as uma na outra, ao mesmo tempo em que murmura algo como "nunca este sangue deixará de manchar estas mãos" - assim parafraseando Lady Macbeth: "All the perfumes of Arabia will not sweeten this little hand." (Shakespeare, 1959). As palavras de Gioconda, originalmente proferidas pela personagem da tragédia shakespeareana logo após o assassinato de um hóspede ilustre, têm caráter extradiegético e transcendem o âmbito da cena que se desenrola na TV: remetem diretamente à trágica realidade de um país que é palco permanente da violência urbana alimentada - não apenas, mas em grande parte 
- pelas elites consumidoras de droga que se fazem clientes fiéis do tráfico e pela parca atenção concedida pelas instâncias governamentais aos problemas gerados pela exclusão social causada, entre outros motivos, pela alta concentração de renda e pelos baixíssimos índices de escolaridade e emprego formal. O estranhamento construído por meio da figura ricamente trajada da refinada, erudita dama da alta sociedade carioca ajoelhada no meio da rua ao lado do miserável cordeiro imolado (a favelada assassinada enquanto caminhava entoando hinos religiosos) cola-se à figura da nobreza ignóbil (que em Shakespeare assassina inocentes prostrados no leito, mergulhados em sono profundo) e, em seguida, descola-se da tela e gruda no destinatário acomodado em frente à telinha. Estetizada, dialógica e intertextual, talvez a cena protagonizada por Lady Gioconda/Macbeth seja mais eficiente, como mola propulsora de conscientização e reflexão, do que o-discurso didático recitado pela mesma Gioconda que, nos capítulos subsequientes, põe-se a transcorrer a respeito da necessidade premente de se fazer alguma coisa em prol da diminuição das desigualdades.

Por caminhos semelhantes transitam ainda outras personagens. Alzira, a mãe de família e dona de casa que travestida em enfermeira deixa o reduto do lar para ganhar a vida dançando na whiskeria da qual Juvenal Antena é sócio - e assim sustentar os filhos pequenos e o marido desempregado e sem saúde -, dialoga com Casa de bonecas, do dramaturgo norueguês Henrik Ibsen, peça que gira em torno de temática semelhante: tal como Alzira, para resolver problemas financeiros decorrentes da doença do marido a protagonista do drama de Ibsen, Nora Helmer, vê-se forçada a lançar mão de recursos pouco recomendáveis do ponto de vista da moral vigente; tal como acontece em Casa de bonecas a face autêntica de Alzira (que brinca de esconde-esconde por entre as máscaras de virtuosa rainha do lar, enfermeira solícita, e despudorada stripper de cabaré) apresenta-se nebulosa ou mesmo irrevelável. Já Maria Eva, a dominadora esposa do executivo que trabalha nas empresas do vilão Ferraço, aficionada por Evita Perón, inspira-se na figura da mulher do outrora presidente argentino para modelar sua vida; extravagante e sedutora, busca orientar na direção que julga ter sido to- 
mada por esta última tanto as investidas afetivas que faz em relação ao marido apaixonado e subjugado e aos demais "súditos" (os familiares e admiradores), quanto seu comportamento social e profissional.

A personagem do intelectual Francisco Macieira, reitor da Universidade Pessoa de Moraes, instituição particular de ensino, parece remeter à figura do polêmico e revolucionário escritor, jornalista e político brasileiro Fernando Gabeira (note-se, a título de curiosidade, a correspondência sonora e mesmo gráfica entre os pares dos significantes Francisco Macieira e Fernando Gabeira) exilado por ocasião da ditadura militar e posteriormente deputado federal pelo Partido Verde do Rio de Janeiro; na ficção, Macieira, que defende a promoção da excelência no setor de ensino de iniciativa privada (questão correlata à atualidade da pauta de discussões no âmbito da Educação no Brasil), tem o propósito declarado de redimensionar a Universidade que dirige, transformando-a em instituição exemplar.

Outras remissões do texto televisivo também podem, com relativa facilidade, serem detectadas, como a referência mais ou menos sutil ao $O$ poderoso chefão ${ }^{10}$, algumas cenas inexplicáveis e misteriosas de Lost $^{11}$ - o seriado de grande sucesso televisivo nos Estados Unidos, que já se encontra na sua quarta fase. No Brasil, o seriado tem sido apresentado pela Rede Globo, mas num horário a que a maioria da audiência das telenovelas não costuma ter acesso, depois da apresentação do Jornal da Globo, que vai ao ar em torno da meia-noite; mas se poucos assistiram ao seriado, bom número de telespectadores tem dele notícias, graças às não poucas matérias produzidas pelas mídias eletrônicas e impressas, que contaram, mos-

10. Longa metragem norte-americano de Francis Ford Coppola, que inaugura a trilogia homônima de muito sucesso no mundo e no Brasil, diferenciada pelos numerais romanos I, II e III. Em 2006, a trilogia foi adaptada para jogos eletrônicos pela Eletronic Arts. Interessante notar que em Portugal o título da trilogia foi traduzido como $O$ Padrinho, designação que o protagonista da telenovela, Evilásio, utiliza-se para se referir a Juvenal Antena.

11. A Rede Globo deve levar ao ar fase inédita do seriado a partir de Fevereiro de 2008; como de costume depois da apresentação do Jomal da Globo. 
traram, comentaram a participação no seriado norte-americano de um galã da teledramaturgia brasileira - Rodrigo Santoro.

Convém frisar, no entanto, que os recursos da intertextualidade empregados em Duas caras, como, aliás, outras telenovelas já o fizeram, não são propriamente para fazer citações eruditas ou emprestar a autoridade da obra referida; prestam-se muito mais a uma intenção prosaica e pragmática, bem própria da televisão, que tende a se apropriar de tudo que já deu certo, principalmente de tudo que provoque alguma dose de emoção. Talvez por isso encontra-se na ordem do dia das narrativas televisivas, vamos dizer, pós-modernas, a divisa de que inovar, quer dizer multiplicar-se ad libitum, é preciso.

\section{Bibliografia}

BALOGH, Anna Maria. $O$ discurso ficcional na TV. São Paulo: EDUSP; 2002.

DANIEL FILHO, O cirćo életrônico: fazendo TV no Brasil. Rio de Janeiro: Jorge Zahar, 2003.

FISCHER, Sandra \& NASCIMENTO, Geraldo Carlos do. "Belíssima: a um passo da ambigüidade - considerações sobre conservadorismo e mudança na novela das oito". In: Revista Comunicação midiática, $\mathrm{n}^{\circ}$ 7, Bauru: Unesp; 2007.

HAMBURGUER; Esther. O Brasil antenado - a sociedade da novela. São Paulo: Jorge Zahar, 2005.

IBSEN, Henrik: Cása de bonecas. São Paulo: Abril Cultural, 1976.

LOPES, Maria Immacolata Vassallo de. (Org.) Telenovela internacionalização e interculturalidade. São Paulo: Edições Loyola, 2004.

LOPES, Maria Immacolata Vassallo de. "Narrativas televisuais e identidade nacional: o caso da telenovela brasileira". In: LOPES, M.I.V: e BUONNAMO, M. Intercom, 2003.

MACHADO, Arlindo. Arte e mídia. Rio de Janeiro: Jorge Zahar, 2007. 
MARTÍN-BARBERO, Jesús. "Viagens da telenovela: dos muitos modos de viajar em, por, desde e com a telenovela". In: LOPES, Maria Immacolata Vassallo de. (Org.) Telenovela internacionalização e interculturalidade. São Paulo: Edições Loyola, 2004.

MARTÍN-BARBERO, Jesús, e REY, Germán. Los ejercicios del ver - hegemonía audiovisual y ficción televisiva. Barcelona: España: Gedisa; 1999.

MOISÉS, Massaud. Dicionário de termos literários. São Paulo: Cultrix, 1999.

SHAKESPEARE, William. The tragedy of Macbeth. New York: Washington Square Press, Inc., 1959.

XAVIER, Ismail. "Do senso moral-religioso ao senso comum pósfreudiano: imagens da história nacional na teleficção brasileira". In: LOPES, Maria Immacolata Vassallo de. (Org.) Telenovela internacionalização e interculturalidade. São Paulo: Edições Loyola, 2004. 